\title{
EFFECTS OF ANOXIA ON THE FLUORESCEIN PERMEABILITY OF THE BLOOD-AQUEOUS BARRIER*
}

\author{
BY
}

\author{
A. GIARDINI AND H. SWANLJUNG
}

From the Institute of Ophthalmology, London

Director of Research, Sir Stewart Duke-Elder.

IT was demonstrated by Giardini and Nižetic (1949), using the Amsler-Huber fluorescein test (1949), that when guinea-pigs are made to breathe air containing approximately 5.52 to 4.16 per cent. oxygen (corresponding to the atmosphere at an altitude of 10-12,000 metres, or 35,000-70,000 feet) for one hour, there is an increase in the concentration of the fluorescein in the anterior chamber. When the fluorescein test was performed on animals which had first breathed a reduced oxygen concentration and had then breathed normal air for half an hour, it was found that these changes were reversible, and that the fluorescein curve again became normal.

For technical reasons these workers were not able to investigate the behaviour of the blood-aqueous barrier during anoxia since their technique entailed such a degree of oxygen-deficiency that serious general disturbances were produced in the experimental animals. In this series of experiments these difficulties have been overcome by the use of an apparatus with which the fluorescein test could be performed during anoxia of the medium-severe type. Cats were used instead of guinea-pigs, partly because the anatomy and physiology of the cat's eye are regarded as being nearer to those of the human eye, and partly because it is possible to inject the fluorescein intravenously in this animal and thus to obtain approximately the same concentration of fluorescein in the blood in all cases.

\section{MeTHOD}

The method of Amsler and Huber (1949) was used for the fluorescein test. To obtain reliable readings it was necessary to reduce the amount of the dye injected to $0.1 \mathrm{ml}$. 5 per cent. solution. The injection was made into the jugular vein, using a tuberculin syringe.

Anoxia was obtained by allowing the animal to breathe a mixture of air and nitrogen from a cylinder connected with a Douglas bag. The mixture was such that the nitrogen diluted the air until it contained only 8.5 per cent. oxygen, thus simulating the oxygen pressure in the atmosphere at an altitude of 7,000 metres $(23,000$ feet). The Douglas bag was connected with a valve system by which the animal could only

- Received for publication November 6, 1950. 
inhale the gas mixture and exhale in the open air. The animal was intubated with a special glass tube, using a small laryngoscope.

The experiments were done under general anaesthesia (nembutal injected intraperitoneally). The larynx and pharynx were painted with 1 per cent. pantocain. Two per cent. homatropin was instilled into both eyes to produce a mydriasis for ease of observation. The chin and head rests of the Haag-Streit slit lamp were removed and the animal was kept in position in a special box. In each animal, successive readings were taken in the same eye at intervals during the first 20 to 30 minutes after injection.

The first experiment was done with the animal breathing normal air through the same apparatus as was used for the induction of anoxia. The second experiment was performed on the same animal, after an interval of at least three days in order that the fluorescein from the first experiment should be totally excreted. In this experiment the animal breathed the gas mixture for 5 minutes before the injection of fluorescein and continued doing so throughout the period of observation.

\section{RESULTS}

Before discussing the results it is necessary to note the peculiarities of the entrance of fluorescein in the anterior chamber of the cat. This is affected by the unusual depth of the cat's anterior chamber and the fact that the fluorescein does not appear to be uniformly distributed throughout the aqueous as in the human eye, but is concentrated in the so-called Ehrlich line. In order to obtain comparable readings, observations were made with the beam of light always in the same position-in the upper temporal quadrant of the anterior chamber. The first reading was not taken until the fluorescein was thoroughly mixed in this region and readings were taken when the green colour was seen to disappear in the middle of the beam of light. During the final part of the experiment the concentration of the dye sometimes became so high that accurate readings were impossible and the experiment had to be terminated.

Each of the twelve cats used showed typical general signs of compensated anoxia; the results obtained are shown in the Table (overleaf). A typical curve is seen in Fig. 1. A summation of the average results is shown in Fig. 2, in which the average values obtained before 10 minutes and after 20 minutes are given in dotted lines, as they were not obtainable in all cases.

The individual readings and the fluorescein curves derived therefrom demonstrate that in all the experiments, with only one exception, the dye appeared more rapidly and in higher concentration in anoxia than when the animals breathed a normal concentration of oxygen, the difference being outside the experimental limits of error (=0.2 amp.). When the animal was breathing normal air a visible concentration of fluorescein sufficient for accurate recording appeared in about 6 to 9 minutes after the fluorescein injection, in the anoxic animal it usually appeared 2 to 3 minutes earlier. After 10 minutes the difference in the concentration of fluorescein in the aqueous of 
TABLE

Corresponding Readings in Animals breathing Normal Air AND UNDER ANOXIA (AMPS).

\begin{tabular}{|c|c|c|c|c|c|c|c|c|c|c|c|c|}
\hline \multirow{3}{*}{ Cat No. } & \multicolumn{6}{|c|}{ Normal Air } & \multicolumn{6}{|c|}{ Anoxia ( 8.5 per cent. oxygen) } \\
\hline & & \multicolumn{5}{|c|}{ Minutes after Injection } & \multicolumn{6}{|c|}{ Minutes after Injection } \\
\hline & & 10 & 15 & 20 & 25 & 30 & 8 & 10 & 15 & 20 & 25 & 30 \\
\hline 1 & 25 & 3.05 & 2.9 & 2.45 & 2.45 & 2.35 & 3.0 & 2.85 & 2.45 & 2.3 & 2.2 & - \\
\hline 2 & 3.0 & 2.9 & 2.35 & 2.3 & 2.2 & 2.2 & 3.5 & 3.0 & 2.4 & 2.15 & 2.1 & - \\
\hline 3 & - & 3.1 & 2.8 & 2.6 & 2.4 & 2.35 & 2.65 & 2.5 & 2.3 & 2.25 & 2.2 & - \\
\hline 4 & 3.55 & 3.0 & 2.5 & 2.45 & 2.35 & 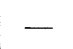 & 2.7 & 2.4 & 2.1 & 2.0 & - & --- \\
\hline 5 & 3.8 & 3.7 & 3.2 & 2.8 & 2.6 & 2.55 & 2.9 & 2.75 & 2.45 & 2.25 & 2.2 & - \\
\hline 6 & 3.4 & 3.3 & 3.05 & 2.75 & 2.7 & 2.65 & 3.5 & 3.3 & 2.7 & 2.5 & 2.4 & 2.35 \\
\hline 7 & 2.95 & 2.7 & 2.4 & 2.3 & 2.25 & 2.25 & 2.4 & 2.25 & 2.1 & 2.0 & 2.0 & - \\
\hline 8 & 3.45 & 3.35 & 3.2 & 3.1 & 2.9 & 2.7 & 3.0 & 2.7 & 2.5 & 2.4 & 2.3 & 2.25 \\
\hline 9 & 3.05 & 2.9 & 2.7 & 2.7 & 2.55 & 2.45 & 2.9 & 2.75 & 2.5 & 2.35 & 2.25 & 2.2 \\
\hline 10 & 5 & 3.0 & 2.6 & 2.35 & 2.25 & - & 2.45 & 2.3 & 05 & 1.95 & 1.95 & - \\
\hline 11 & 3.8 & 3.4 & 2.8 & 2.75 & 2.6 & 2.5 & 2.55 & 2.35 & 2.1 & 1.95 & 1.95 & $\ldots$ \\
\hline 12 & 3.7 & 3.4 & 3.0 & 2.9 & 2.7 & 2.6 & 3.25 & 3.05 & 2.6 & - & - & - \\
\hline che & 3.38 & 3.23 & 2.79 & 2.62 & 2.5 & 2.49 & 2.9 & 2.68 & 2.35 & 2.19 & 2.16 & - \\
\hline
\end{tabular}

the normal and anoxic animals was equivalent to 0.65 amps., after 15 minutes to 0.45 amps., and after 20 minutes to 0.4 amps. It is interesting that the curves resemble those obtained in human beings, showing an initial steeper rise in concentration and running almost horizontally at the end of the experiment. The two curves obtained in the same animal when breathing normal air and during anoxia are almost parallel and the difference between them tends to decrease towards the end of the period of observation. The corresponding values in different animals, however, seem to vary considerably since the same quantity of the dye was always used. This difference may to some extent be due to the difference in the size of the animals, the weights of which varied between 1.6 and $3.4 \mathrm{~kg}$.

\section{Discussion}

In discussing the results, two constituents of the blood-aqueous barrier must be taken into consideration: the capillary walls of the 


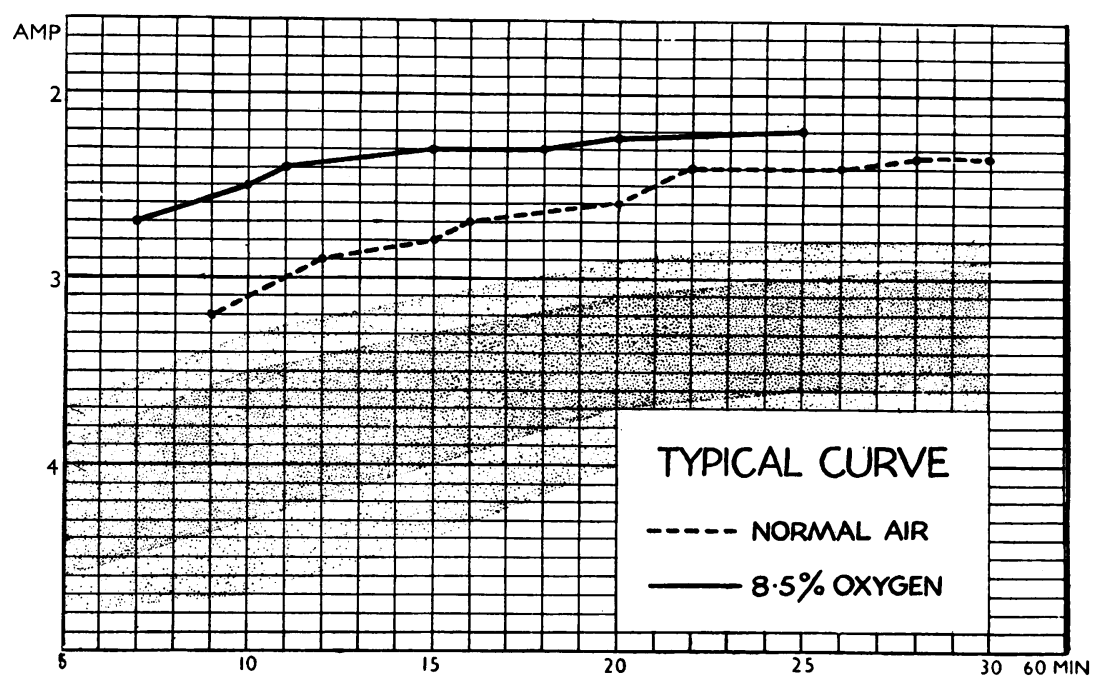

FIG. 1.-Typical fluorescein curve

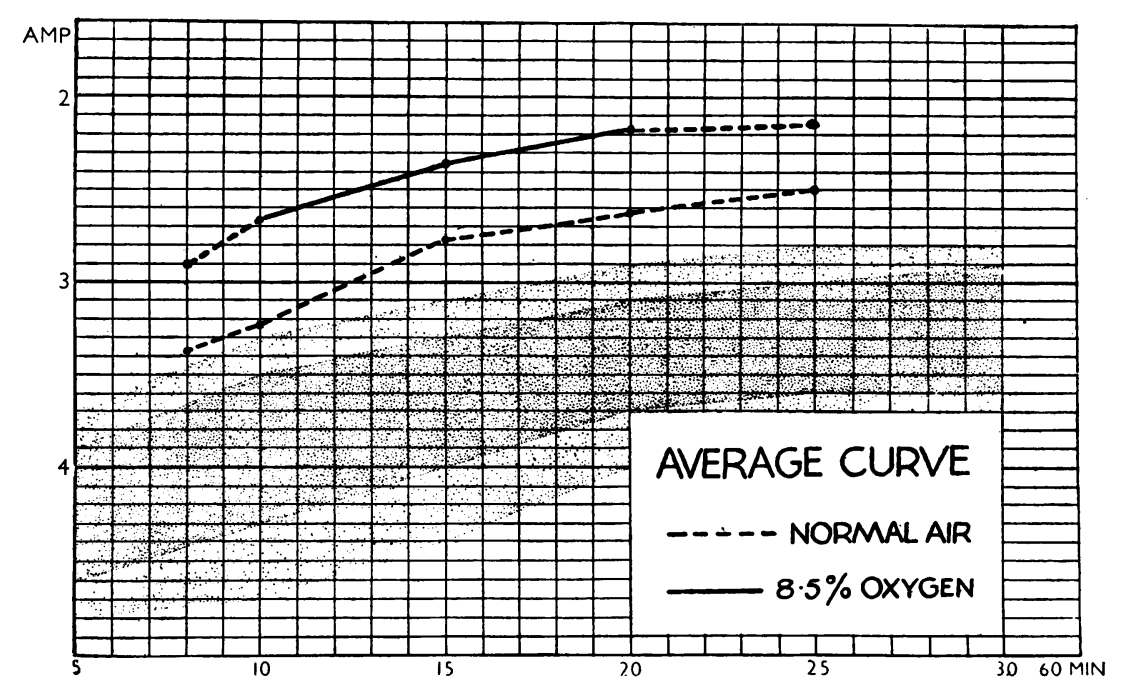

FIG. 2.-Average of fluorescein curves

ciliary body, and the ciliary epithelium. The first of these seems to be the more important; any effect which anoxia may have upon the ciliary epithelium is quite unknown.

So far as the ocular vessels are concerned, it is known that important changes occur during anoxia. On ophthalmoscopic examination several authors have found dilatation of the retinal arteries and veins (Cusick, Benson, and Boothby, 1940; Mercier 
and Duguet, 1947), and an increase of the systolic and diastolic pressures of the central retinal artery (Bietti and Lo Monaco-Croce, 1941; Duguet, Dumont, and Bailliart Jr., 1947). The behaviour of the retinal capillaries has been studied by the endoscopic method (Zeiss entoptoscope), and during anoxia a reduction in the diameter of the capillaries has been found with an increase in the speed of the erythrocytes (Bietti and Lo Monaco-Croce, 1941). Duguet, Dumont, and Bailliart Jr. (1947), however, using the Fortin entoptoscope, were unable to reach any conclusion.

A further clue may be derived from the valuable work of Landis (1928). Using a capillary in the mesentery of a decapitated frog in oxygen deficiency, he demonstrated an increased transudation and the passage of proteins through the vessel wall so that the osmotic pressure within the capillary was reduced by half. It would seem that in anoxia the capillary wall acts as a passive filter, since the movement of fluid through the wall is directly proportional to the difference between the capillary pressure and the osmotic pressure of the proteins of the plasma.

The increased passage of the smaller fluorescein molecule through the capillary walls of the ciliary body in anoxia could thus be explained as a result of increased permeability. A review of the literature shows that in anoxia there is either a slight increase or none in the intra-ocular pressure; but it is also known that conditions of increased permeability do not necessarily determine such an increase.

\section{SUMMARY}

(1) Experiments were carried out to determine the relationship between oxygen deficiency and alterations in permeability of the blood-aqueous barrier.

(2) The Amsler-Huber fluorescein test was performed on cats, first breathing normal air, and then after a few days breathing a gas mixture containing 8.5 per cent. oxygen, simulating the atmosphere at an altitude of $7,000 \mathrm{~m}$. $(23,000 \mathrm{ft}$.). In all but one of these animals under anoxia there was an increased fluorescein concentration in the anterior chamber.

(3) The possible mechanism of the action of oxygen deficiency on the blood-aqueous barrier is discussed.

\section{REFERENCES}

Amsler, M., and Huber, A. (1949). Graefes Arch. Ophthal., 149, 578.

Bietti, G. B., and Lo Monaco Croce, T. (1941). Riv. Med. aeronaut., 4, 177.

Cusick, P. L., Benson, O. O., and Boothby, W. M. (1940). Proc. Mayo Clin., 15, 500.

Duguet, J., Dumont, P., and Ballliart, J. P. (1947). Méd. aeronaut., 2, 201.

Giardini, A., and Nižetić, B. (1949). Atti 38 Congr. Soc. Oftal. Ital., 11, 444

LANDIS, E. (1928). Amer. J. Physiol., 83, 528.

MerCIER, A., and Duguet, J. (1947). "Physio-pathologie oculaire de l'aviateur", Société d'Ophtalmologie de Paris. 